\title{
Restructuring a New Approach of Pun Translation Strategy*
}

\author{
Chengzhi Zhang (Corresponding Author) \\ School of Foreign Languages, Hebei University, Baoding, Hebei, China \\ Goh Sang Seong \\ School of Humanities, Universiti Sains Malaysia, Penang, Malaysia \\ Suzana Hj. Muhammad \\ School of Humanities, Universiti Sains Malaysia, Penang, Malaysia
}

\begin{abstract}
The objective of the paper is to examine Delabastita's approach of pun translation strategies in English-Chinese translation. 121 puns in Shakespeare Sonnets and their nine Chinese translations are taken as the research corpus. Nida's CAM was taken to analyze the puns' meanings. The research identified a new strategy some major defects in his approach. And a new approach of pun translation strategy is proposed.
\end{abstract}

\section{Index Terms-Shakespeare's Sonnets, pun, translation strategy}

Many scholars attest that puns are difficult to translate. Newmark (2001, p. 12) indicates "Puns made by punning poets are most difficult to translate, since they are limited by meter. Often the puns simply have to be sacrificed". Reiss (2000, p. 169) admits, "In translation puns and other kinds of play with language will have to be ignored to a great extent so as to keep the content invariant." Han Dihou (1969, p. 37) even claims that "The problem of pun cannot be resolved by any translation theory." Nevertheless, Delabastita (1993) proposes an approach of pun translation strategies, which brings a theoretical breakthrough into the translation of puns.

\section{Delabastita’s ApProach of Pun Translation Strategies}

Delabastita (1993, pp. 191-218) proposes 9 strategies for the translation of puns:

(1) pun to pun; in which the ST pun was transferred into a TT pun, which may or may not share the same properties of the ST pun.

(2) pun to non-pun, in which the original pun was transferred into a TT word or phrase, which may preserve one or more senses of the original pun. In this category, there are three possibilities: non-selective non-pun, selective non-pun, and diffuse paraphrase

(i) Nonselective non-pun. Both of the original meanings are rendered -hence the term non-selective - but in a nonpunning conjunction.

(ii) selective non-pun. One of the two linguistic meanings of the S.T. pun has been selected and translated more or less equivalently, while the other has been selected - hence the term selective.

(iii) Diffuse paraphrase. The original meanings have been translated 'beyond recognition due to the rather free treatment of the entire punning passage.

(3) pun to punoid, in which the translator has perceived the original pun, and tried to recreate its effect by using some other wordplay-related rhetorical devices, such as repetition, assonance, irony allusion, and etc.

(4) zero translation, in which the original pun is simply omitted

(5) Direct copy: in which the translator reproduces the ST pun in its original form, i.e. without actually "translating" it.

(6) Transference, like (5) direct copy. The difference is that it imposes source language signified on a target language text, while the method of direct copy brings the original signifiers into the T.T. without any necessary concern about the semantic consequences of it.

(7) Addition: non-pun to pun. The T.T. contains wordplay which the ST does not have. Its purpose is to compensate the loss of those puns that the translator is unable to render appropriately in their original position.

(8) Addition (new textual material): zero to pun. The translator added in T.T. a new pun which is impossible to identify a counterpart in the S.T.

\footnotetext{
* This paper is a fruit of the research grant, A Corpus-based Study on the Translation of Financial Terms, approved by The Education Department of Hebei Province, Registration No. SQ141163.
} 
(9) editorial technique. It includes a whole range of phenomena: articles by the translator published in a periodical or in a volume; introduction, epilogue and etc. within the volume; footnotes and endnotes; parentheses within the primary text, but distinguished from it by means of square brackets, italics, etc.

His proposal is fairly influential in pun translation. Chang Nam Fung (2003, p. 33) asserts that Delabastita's theory can also be applied in English-Chinese translation. However, Delabastita's corpus is Hamlet's Dutch, French and German translations, instead of English-Chinese translation. And his approach has never been examined in EnglishChinese translation. Therefore, this paper aims to discuss the application of Delabastita's approach in the context of English-Chinese translation.

\section{Methodology AND TheORETICAL FRAMEWORK}

The analysis examines the 121 puns in Shakespeare Sonnets and its nine Chinese translations, namely, Tu An's version (1981), Yu Erchang's version (2002), Liang Shiqiu's version (2002), Yang Xiling's version (1980), Liang Zongdai's version(1983), Cao Minglun's version (1995), Gu Zhengkun's version (1998), Ruan Shen's version (2001), Jin Fashen's version (2004). Shakespeare Sonnets is chosen as the research corpus because Shakespeare is identified to be a master of puns himself. As Drabble (2000, p. 825) states, "(Shakespeare was) greatly given to punning, both in comic and in serious contexts". Li Xinhua (2000, p. 198) points out, "Shakespeare was a great master of creating puns. According to incomplete statistics, Shakespeare had created more than 3,000 puns in his works." In addition, Shakespeare Sonnets is a great piece in English literature and even world literature. What's more, there are at least 9 complete Chinese versions, which provide rich research data for the study.

The original meanings of puns are mainly identified by the editions of Ingram \& Redpath (1978), Stephen Booth (1977) and Helen Vendler (1997). According to Larudee's (1973) definition, pun is a play on words, in which two or more meanings are expressed in one form. And one unique feature of pun is that it incorporates two or more disparate yet acceptable messages in one form, and the form plays a very important role. Therefore, the essential nature of a pun is two or more meanings in one form. The form refers to the sound. And the meanings and form are two major constituents of a pun. It will be used to help identify the pun in SS, analyze the translation of puns in terms of form (sound), meaning and form plus meaning. Componential Analysis of Meaning (CAM) of Nida (1973) will be utilized to analyze the translatability meaning, whereas the Chinese Pinyin and IPA will be applied to analyze the translation of form (sound). Delabastita's (1993) strategies will be applied in identifying the translation strategies of puns in Shakespeare's Sonnets.

\section{TRANSLATION STRATEGIES}

The research finds that the following strategies of Delabastita's approach have been identified among the 121 puns' nine Chinese translations.

\section{A. Pun-pun Strategy}

In the first line of Sonnet 135,

Whoever hath her wish, thou hast thy 'Will' (Ingram \& Redpath, 1978, p. 313)

Will is a semantic pun, which conveys two meanings: (M1) wishes; (M2) lust (ibid, p.312). One renders the pun as 欲(yu, wishes) (Cao Minglun, 1995, p. 204). Figure 1 shows the meaning features of both the original pun and the translation.

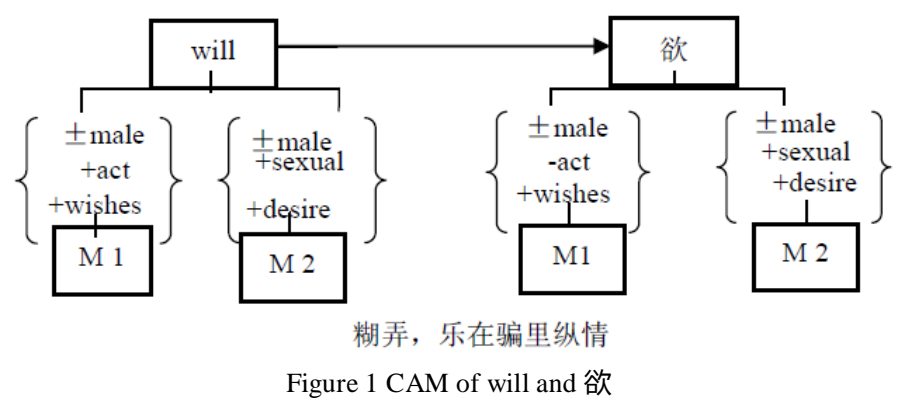

Figure 1 shows that 欲(yu, wishes) conveys two meaning, the first meaning preserves the original M1, because its meaning components are completely the same to those of M1: [ \pm male], [+act], [+wishes]. The second meaning preserves the original M2, because its meaning components are completely the same to those of M2: [ \pm male], [+sexual], and [+desire]. As it conveys two meanings in one form, thus it is also a pun. And both of the original meanings have been successfully preserved by the pun. Thus, it is a pun-pun strategy.

\section{B. Pun to Non-pun Strategy}


Delabastita divides the strategy into three subtypes: (i) nonselective non-pun, (ii) selective non-pun strategy, and (iii) diffuse paraphrase. All of the three subtypes are identified in the study.

(i) Nonselective Non-pun

In the $5^{\text {th }}$ line of Sonnet 43 ,

Then thou, whose shadow shadows doth make bright (Ingram \& Redpath, 1978, p. 101).

Shadow is a semantic pun, which conveys 2 meanings: (M1) image; (M2) darkness (ibid, p.100). One renders the pun as 黑影(heiying, black shadow) (Tu An, 1981, p. 43). Figure 2 shows the meaning features of both the original pun and the translation.

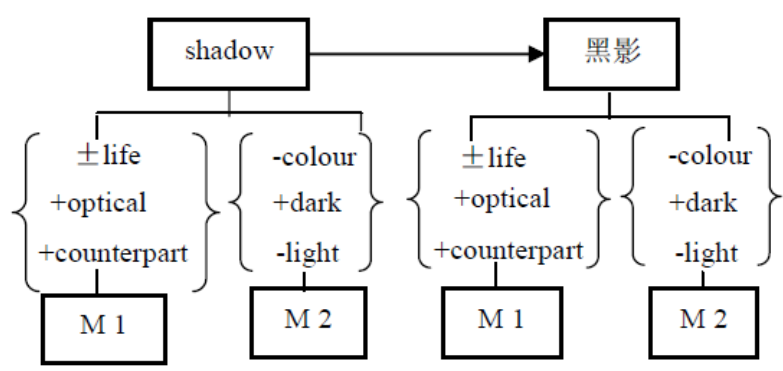

Figure 2 CAM of shadow and 黑影

Figure 2 shows that 黑影 (heiying, black shadow) conveys two meaning, the first meaning preserves the original M1, because its meaning components are the same to those of M1: [ \pm life], [+optical], and [+counterpart]; The second meaning preserves the original M2, because its meaning components are the same to those of M2: [-colour], [+dark], and [-light]. However, it is not a pun itself. The two independent characters happen to convey each of the original meaning. And both of the original meanings are successfully preserved in this non-pun phrase. Thus, it is a nonselective non-pun strategy.

(ii) Selective Non-pun Strategy

In the 14th line of Sonnet 138,

And in our faults by lies we flatter'd be (Ingram \& Redpath, 1978, p. 319)

Lie is a semantic pun, which conveys two meanings: (M1) To tell a lie; (M2) To sleep with another man (Booth, 1977, pp. 477-478). One renders the pun as 撒谎 (sahuang, tell a lie) (Jin Fashen, 2004, p. 138). Figure 3 shows the meaning features of both the original pun and the translation.

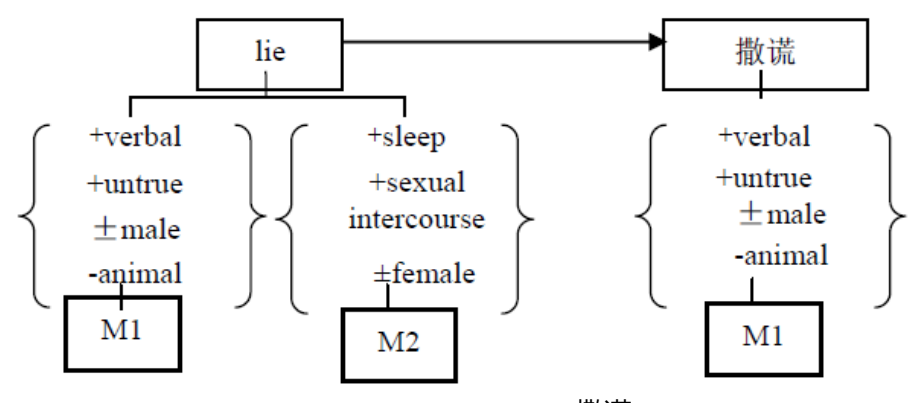

Figure 3 CAM of lie and 撒谎

Figure 3 shows that 撒谎(sahuang, tell a lie) preserved only the first meaning, since its meaning components are the same to those of the original M1, while the second meaning is lost in translation. And it is not a pun itself. Therefore, it is selective non-pun strategy.

In the $2^{\text {nd }}$ line of Sonnet 134 ,

And I myself am mortgaged to thy will, (Ingram \& Redpath, 1978, p. 311).

Will is a semantic pun, which has two meanings: (M1) wishes; (M2) lust. One rendered the pun as 意愿 (yiyuan, wishes) (Tu An, 1981, p. 134). Figure 4 shows the meaning features of both the original pun and the translation. 


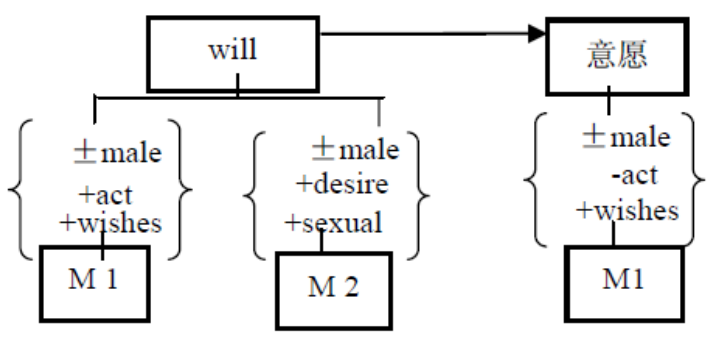

Figure $4 \mathrm{CAM}$ of will and 意愿

Figure 4 shows that 意愿 (yiyuan, wishes) preserved only the first meaning, since its meaning components are the same to those of the original M1, while the second meaning is lost in translation. It is not a pun itself. Therefore, it is selective non-pun strategy.

(iii) Diffuse Paraphrase

For example, in the $14^{\text {th }}$ line of Sonnet 138 ,

And in our faults by lies we flatter'd be (Ingram \& Redpath, 1978, p. 319).

Lie is a semantic pun, which conveys two meanings: (M1) To tell a lie; (M2) To sleep with another man (ibid, p318). One renders the pun as 糊弄，乐在骗里纵情 (hunong, lezai pianli zongqing, cheat each other, pleased to enjoy ourselves in lies) (Gu Zhengkun, 1998, p. 277). Figure 5 shows the meaning features of both the original pun and the translation.

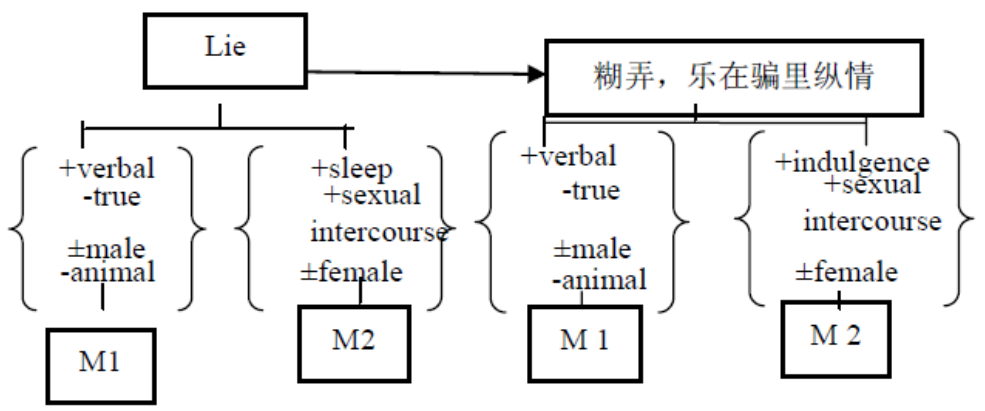

Figure 5 CAM of lie and 糊弄, 乐在骗里纵情

Figure 5 shows that it conveys two meanings. The first meaning is conveyed through “糊弄” and “骗”, meaning to deceive, which preserved the original M1 (to tell a lie), since their meaning components are the same to those of M1. The second meaning is conveyed by “乐在...纵情”, whose meaning components is the same to those of the original M2. The translation preserves the original two meanings. Both “糊弄”, and “骗” are literal translations of the first meaning, while “乐在骗里纵情” is virtually a paraphrase of the second meaning. As it is a rather free treatment of the original pun, its translation strategy is diffuse paraphrase.

\section{Zero Translation}

In the 4th line of Sonnet 30,

And with old woes new wail my dear time's waste: (Ingram \& Redpath, 1978, p. 75).

Dear is a semantic pun, which conveys two meanings: (M1)costly; (M2) held in high esteem(ibid, 1978, p. 360). One renders the line as:

再度因时间摧毁了好宝贝而哀伤：(Tu An, 1981, p. 30)

Again because time destroy good treasure thus wail

Clearly, none of the original meanings exist in the translation. No counterpart to the original pun could be identified in the translation. Therefore, it is a zero translation.

In the $10^{\text {th }}$ line of Sonnet 151 ,

As his triumphant prize. Proud of this pride (Ingram \& Redpath, 1978, p. 349).

Proud is a semantic pun, which has four meanings: (M1)vainglorious; (M2) splendid, gorgeous; (M3)lustful; (M4) swollen (Booth, 1977, p. 528). One renders the line as:

你是他凯旋的奖品，夙愿得偿 (Jin Fashen, 2004, p. 151).

you are his victory prize, dream realized 
No counterpart to the original pun could be identified in the translation. Therefore, it is a zero translation, which preserves neither the meaning nor the form of the original pun.

\section{Editorial Techniques}

Editorial techniques in fact help translators to establish a second level of communication, which allows them to introduce the background knowledge or to reflect and comment on the translation. It includes "a whole range of phenomena: articles by the translator published in a periodical or in a volume; introduction, epilogue and etc. within the volume; footnotes and endnotes; parentheses within the primary text, but distinguished from it by means of square brackets, italics, etc" (Delabastita, 1993, p. 218). In this study, the following techniques are identified: quotation marks, footnotes, endnotes, and bold font as well.

1. Quotation Marks

For example, in the $8^{\text {th }}$ line of Sonnet 148 ,

Love's eye is not so true as all men's 'No' (Ingram \& Redpath, 1978, p. 349).

The homonymic pun, eye, conveys two meanings (M1) eye; (M2) yes (Booth, 1977, p. 521). One translates this line into this,

爱“眼力”并没有众人那么真 : 不，(Jin Fashen, 2004, p. 148)

Love "eye power" not others so true: no

He renders "eye" as 眼力 (yanli, meaning power of eyes or eyesight), which preserves only the first meaning, however, the point here is the translator added a pair of quotation marks to his translation, which is to stress the word and attract readers' attention. Quotation marks are a subtype of editorial techniques, which belongs to the ninth strategy.

2. Footnote

For example, in the $12^{\text {th }}$ line of Sonnet 151 ,

Yet who knows not conscience is born of love? (Ingram \& Redpath, 1978, p. 349).

The pun lies in conscience, which conveys two meanings: (M1) ability to recognize right and wrong; (M2) knowledge of sex (ibid, p349). One renders the line as:

可谁不知晓良知是由爱心唤醒 ? (Cao Minglun, 1995, p. 238).

But who not know conscience is by love waken?

He renders “conscience” as “良知”, which successfully preserves the original meanings through a semantic pun. Furthermore, he also makes a foot note to his translation, "Conscience is a pun. On one hand, it expressed the then popular concept that love exalts the lover. On the other hand, man of letters in that age often use it as the euphemism of con in French, which implies sexual intercourse, therefore, conscience means knowledge of con"(ibid, p241). Footnotes are editorial techniques in puns' translation, which belongs to the ninth strategy of Delabastita's approach.

3. Endnote

For example in the $1^{\text {st }}$ line of Sonnet 135 ,

Whoever hath her wish, thou hast thy 'Will' (Ingram \& Redpath, 1978, p. 313)

The pun word "will” conveys two meanings: (M1) wishes; (M2) lust (Booth, 1977, p. 466). One rendered the line as:

不管别人如何，你是欲望满足了 (Liang Shiqiu, 2002, p. 183).

No matter others how, your desire satisfied

He renders “will” as 欲望 (yuwang, sexual desire), which preserves the second meanings only, however, Liang makes an endnote, "Will is a pun here, it may refer to the poet himself, or his friend, or the lady's husband. Also it means desire" (Liang Shiqiu, 2002, p. 225). Endnotes help readers to understand the pun. Endnotes, like footnotes, are editorial techniques in puns' translation, which belongs to the ninth strategy of Delabastita's approach.

4. Bold Font

In the $14^{\text {th }}$ line of Sonnet 136 ,

And then thou lovest me, for my name is 'Will' (Ingram \& Redpath, 1978, p. 315).

Shakespeare puns on "will”, which conveys four meanings: (M1) wishes; (M2) lust; (M3) sex organ; (M4) William (Booth, 1977, p. 466). Yang's translation is:

那你就会爱我，因我名叫威廉 : 意愿。(Yang Xiling, 1980, p. 136)

You will love me, because my name is William: Will

He rendered “will” as 威廉 : 意愿 (weilian: yiyuan, William and wishes). Furthermore, the translation, 威廉 : 意愿 (weilian: yiyuan, William and wishes) was printed in bold fonts, which is to stress the word and draw readers' attention. Here the translator virtually used an editorial technique, bold fonts, to help with his translation. It is a subtype of the ninth strategy.

\section{E. Summary}

Table 1 shows the translation strategies used by all the nine translators. 
TABLE 1

TRANSLATION STRATEGIES BY THE NINE TRANSLATORS

\begin{tabular}{|c|c|c|c|c|c|c|c|c|c|c|c|c|c|}
\hline \multirow{2}{*}{$\begin{array}{l}\text { Strategies } \\
\text { translator }\end{array}$} & \multirow{2}{*}{ (1) } & \multicolumn{3}{|c|}{ (2) } & \multirow{2}{*}{ (3) } & \multirow{2}{*}{ (4) } & \multirow{2}{*}{ (5) } & \multirow{2}{*}{ (6) } & \multirow{2}{*}{ (7) } & \multirow{2}{*}{ (8) } & \multirow{2}{*}{ (9) } & \multirow{2}{*}{ \# } & \multirow{2}{*}{ Transliteration } \\
\hline & & $\mathrm{i}$ & ii & iii & & & & & & & & & \\
\hline Tu An & 5 & 1 & 98 & 0 & 0 & 8 & 0 & 0 & 0 & 0 & 3 & 0 & 6 \\
\hline Yu Erchang & 3 & 4 & 73 & 0 & 0 & 20 & 0 & 0 & 0 & 0 & 15 & 0 & 14 \\
\hline Liang Shiqiu & 1 & 0 & 84 & 0 & 0 & 20 & 0 & 0 & 0 & 0 & 4 & 0 & 6 \\
\hline Yang Xiling & 3 & 0 & 97 & 1 & 0 & 9 & 0 & 0 & 0 & 0 & 2 & 1 & 2 \\
\hline Liang Zongdai & 2 & 0 & 95 & 0 & 0 & 12 & 0 & 0 & 0 & 0 & 4 & 0 & 0 \\
\hline Cao Minglun & 17 & 1 & 84 & 0 & 0 & 12 & 0 & 0 & 0 & 0 & 5 & 0 & 0 \\
\hline Gu Zhengkun & 21 & 0 & 71 & 3 & 0 & 15 & 0 & 0 & 0 & 0 & 1 & 0 & 1 \\
\hline Ruan Shen & 6 & 1 & 86 & 0 & 0 & 15 & 0 & 0 & 0 & 0 & 0 & 1 & 0 \\
\hline Jin Fashen & 2 & 2 & 89 & 0 & 0 & 16 & 0 & 0 & 0 & 0 & 13 & 0 & 0 \\
\hline total & 60 & 9 & 777 & 4 & 0 & 127 & 0 & 0 & 0 & 0 & 46 & 2 & 29 \\
\hline
\end{tabular}

Table 1 shows: (1) The third, the fifth, the sixth, the seventh and the eighth strategies are not identified among the nine translations of the 121 puns. (2) There are two translations which cannot fit into any category of Delabatsita's approach, see Column \#. (3) Delabastita's approach misses one strategy: transliteration, which has been used by five translators for 29 times.

1. Unexplainable Examples

In case where a pun conveys three or more meanings, a translator preserves two or more of the original meanings through a non-pun phrase. It might be classified as a subtype of pun-to-non-pun strategy, however, it is different to its three subtypes. The three substrategies are based on the hypothesis that the original pun has two meanings only. In case where a pun has three or more meanings, his approach would not be available. For example, in the $10^{\text {th }}$ line of Sonnet 151 ,

As his triumphant prize. Proud of this pride, (Ingram \& Redpath, 1978, p. 349)

Proud is a semantic pun, which has four meanings: (M1) vainglorious; (M2) splendid, gorgeous; (M3) lustful; (M4) swollen (Booth, 1977, p. 528). One rendered the pun as 欲念膨胀(yunian pengzhang, lust expanded) (Ruan Shen, 2001, p. 303). Figure 6 shows the meaning features of both the original pun and its translation.

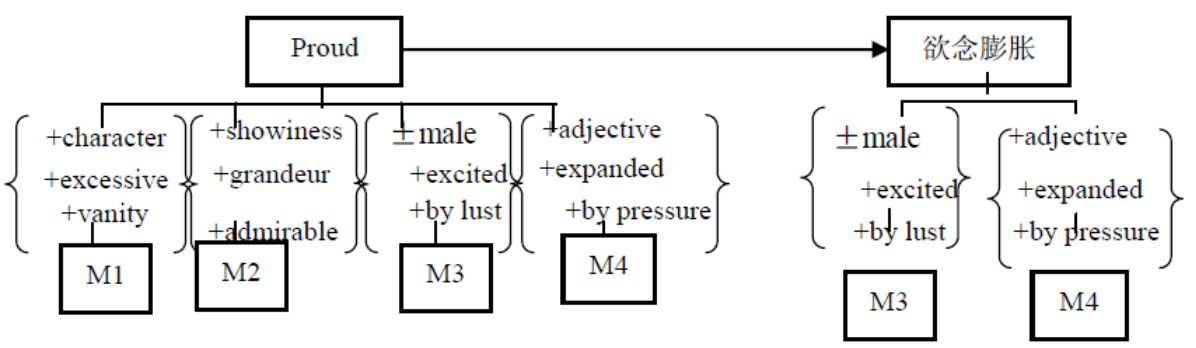

Figure 6 CAM of proud and 欲念膨胀

Figure 6 shows 欲念膨胀(yunian pengzhang, lust expanded) conveys two meanings, one is associated with sexual lust, which is equivalent to M3, because they both contains the kernel component of [+by lust]; the other means to expand, which is equivalent to M4, because both contains the kernel meaning component of [+expanded]. Regretfully, it fails to preserve the other two meanings. It renders the original pun into a non-pun phrase, thus it seems best to classify it as a pun-to-nonpun strategy. However, none of the three subcategories of pun-to-nonpun strategy could match it, since the original pun conveys 4 meanings. Delabastita's approach can not explain this translation.

2. Missed Strategy: Transliteration

In the $1^{\text {st }}$ line of Sonnet 135 ,

Whoever hath her wish, thou hast thy 'Will' (Ingram \& Redpath, 1978, p. 313).

Will is a semantic pun, which has two meanings: (M1) wishes; (M2) lust (Booth, 1977, p. 466). Its form,

International Phonetic Alphabet (IPA), is [wil]. A translator renders the pun as 玩儿(wan'er, play) (Yu Erchang, 2002, p. 271), which is very close in pronunciation to the original pun's form. It is a transliteration to the original pun which preserves the form but loses the meaning of the original pun.

For another example, in the $5^{\text {th }}$ line of Sonnet 136 ,

'Will' will fulfil the treasure of thy love, (Ingram \& Redpath, 1978, p. 315).

Will is a mixed pun, which has four meanings: (M1) wishes; (M2) lust; (M3) sex organ; (M4) William (Booth, 1977, p. 466). Its form, International Phonetic Alphabet (IPA), is [wil]. One renders the pun as 威尔 (Wei'er, meaningless) (Tu An, 1981, p. 136), which is very close to the original pronunciation. Virtually it is a transliteration to the original pun. Though the original meanings are lost, the form is preserved successfully. Thus, it is a transliteration strategy. Similarly, another translator renders it as 威廉 (weilian, William) (Liang Shiqiu, 2002, p. 185), which is also a 
transliteration of the pun. However, Delabastita's approach does not mention transliteration as a translation strategy of puns at all.

Transliteration is similar to (5) Direct copy in nature. By using the strategy of direct copy, the translator reproduces the ST pun in its original form, i.e. without actually translating it at all. Both are applied to preserve primarily the form of the original pun. Due to the great linguistic difference between English and Chinese, direct copy is rarely acceptable in English-Chinese translation of puns.

\section{WEAKNESSES IN DELABASTITA’S APPROACH}

In the research, the following weaknesses are found in Delabastita's approach.

(i) Non-selective non-pun and (iii) diffuse paraphrase shall be told apart from (ii) selective non-pun, because the former preserves two or more meanings while the latter preserves one meaning only. Though Delabastita categorizes them all into the second strategy, they are essentially different. As a pun conveys two or more meanings, both (i) and (iii) suggest the translator must have identified the puns, and have taken some measures to preserve two or more of the original meanings, whereas (ii) might imply that the translator might have failed to recognize the puns and thus preserves one meaning only, therefore, they are totally different from (iii) in nature. What's more, as Table 2 shows, among the 790 cases where the second strategy is used, (ii) is used for 777 times, while (i) and (iii) are used altogether 13 time s only. Both (i) and (iii) are used much less than (ii).

TABLE 2

\begin{tabular}{|c|c|c|c|}
\hline $\begin{array}{ll}\text { items } & \text { Strategies } \\
\end{array}$ & $\overline{\mathrm{i}}$ & ii & iii \\
\hline total & 9 & 777 & 4 \\
\hline
\end{tabular}

Table 2 implies that the vast majority of puns in Shakespeare Sonnets might have been ignored by translators, and that only in very few cases, the translators have identified the puns and made efforts to preserve the meanings. This deserves more attention considering the fact that Shakespeare is a great punster, and that he uses a lot of puns in his sonnets. Therefore, it is necessary to tell (i) and (iii) from (ii), first for the difference in nature, secondly for the purpose of drawing translators' attention.

(i) Non-selective non-pun and (ii) selective non-pun are not well termed and needs modification. The following are how Delabastita (1993, pp. 202-204) defines the two terms:

(i) Non-selective non-pun. Both s1 (ST) and s2 (ST) are rendered -hence the term non-selective - but in a nonpunning conjunction.

(ii) Selective non-pun. One of the two linguistic meanings of the ST pun has been selected and translated more or less equivalently, while the other has been selected - hence the term selective.

S1 and S2 refer to two different meanings. Delabastita here suggests that puns convey two meanings only. Thus, (i) Non-selective non-pun means both S1 and S2 are preserved in translation, while (ii) Selective non-pun means one of the original meanings is selected to be preserved. However, many puns have three or more meanings. Take Shakespeare Sonnets as an example, according to the researcher's observation, there are 18 puns with three meanings and 12 puns with four meanings, which altogether constitute $24.7 \%$ of the total 121 puns. Therefore, his definition is inaccurate. It is also confusing in classifying the translation strategies. For example, in the $10^{\text {th }}$ line of Sonnet $151 / 10$,

As his triumphant prize. Proud of this pride, (Ingram \& Redpath, 1978, p. 349)

The pun word, proud, has four meanings: (M1) vainglorious; (M2) splendid, gorgeous; (M3) lustful; (M4) swollen, tumescent(Booth, 1977, p. 528). One renders the line as:

视你为战利品，欲念膨胀 (Ruan Shen, 2001, p. 303)

Regard you as trophy, lust swollen

The original pun is rendered as 欲念膨胀 (yunian pengzhang, lust is swollen). The first two characters preserve the third meaning, while the other two characters conveys the fourth meaning. It is not a pun, but it preserves two of the four original meanings. The problem emerges. Obviously, it is unpersuasive to put it under (i), since the pun conveys 4 meanings and the translator does select two meanings to preserve, nor under (ii), since it preserves two meanings instead of one. Virtually, in cases where a pun conveys three or more meanings, it is difficult to identify the translation strategies due to the poor definition.

Delabastita terms the second strategy as pun>non-pun, which is also a poor term, especially considering he terms the first strategy as "pun>pun". By such classification, there would be two categories of pun translation strategies only, either pun>pun or pun>non-pun, as all other strategies, (except (9), which is not a translation strategy in nature, but a compensation instead), namely, (3), (4), (5), (6), (7) and (8), shall be regarded as subtypes of the latter.

Delabastita's eighth strategy, addition, is virtually not a strategy of translating puns. He defines it as "zero to pun", in which the translator adds in T.T. a new pun "which is impossible to identify a counterpart in the S.T." (Delabastita, 1993, p. 217) that is, the translator translates the original, which is not a pun at all, with a pun. The precondition of any 
pun translation strategy is that the ST must be a pun. Without this, pun translation strategy could not possibly be applied. Judged by this, the eighth strategy shall not be considered as a pun translation strategy at all.

Delabastita's approach is based on Hamlet's Dutch, French and German translations, instead of English-Chinese translation, thus bears some Eurocentric bias, that is why the other four strategies are not applied in the nine versions, and that a new strategy is missed in his approach. Thus a new approach is needed. For the reasons above and on the basis of his approach and this research, a new approach of pun's translating strategies is proposed, which will diminish the weak points in Delabastita's strategies. Its basic principle is that the translation strategies of puns shall be divided into two categories: translating strategies and supporting strategies.

\section{A New Approach of Pun Translation Strategies from English into Chinese}

Pun translation strategies are composed of two categories: translating strategies and supporting strategies.

\section{A. Translating Strategies}

Translating strategies aims to preserve the form, meaning, or both of the original pun, which consist of five subcategories, pun-to-pun strategy, two-meaning strategy, one-meaning strategy, zero-meaning strategy, and transliteration.

Pun to pun, in which the SL pun is translated into a TL pun, which may or may not preserve all the meanings of the SL pun. It is basically the same to Delabastita's first strategy. In this study, among the 121 pun's nine translations, the strategy is used for 59 times altogether by nine translators. The strategy may preserve all of the original meanings. However, it may also lose some meanings. As long as the translation is a pun, it shall be classified as pun-to-pun strategy. Its advantage is that it helps preserved the original's rhetoric feature.

Two-meaning strategy ${ }^{1}$, in which the TT fragment, which is not a pun itself, preserves two or more of the original meanings. It is equivalent to Delabastita's (i) selective non-pun and (iii) diffuse paraphrase of the second strategy. When the translator identifies the original pun and feels difficult to render it into a TL pun, this strategy helps.

One-meaning strategy, in which only one of the original meanings conveyed by the SL pun is preserved and the other meaning or meanings are lost. It is basically the same to Delabastita's (ii) selective non-pun of the second strategy.

Zero-meaning strategy, in which no counterpart to the original pun can be found or the original pun is simply omitted in the translation. It is equivalent to Delabastita's zero translation strategy.

Transliteration, in which the pun is translated by some Chinese characters which has the same or similar pronunciation with the original. Usually, the original meanings are lost in transliteration unless the pun happens to be the name of a person or a place.

Each translating strategy should be used alone, except transliteration, which could be applied along with pun-to-pun strategy, two-meaning strategy, or one-meaning strategy. For example, in the $14^{\text {th }}$ line of Sonnet 136, one rendered “will” as 威廉：意愿 (weilian yiyuan, William and wishes) (Yang Xiling, 1980, p. 136) see 3.3.4, in which transliteration is used together with two-meaning strategy.

\section{B. Supporting Strategies}

This study identifies supporting strategies as a wide range of editorial techniques including footnotes, endnotes, special fonts, quotation marks, the introduction and epilogue within the volume and etc. They are not at all the translations of the original pun, and preserve nothing of the original pun, the form, the meaning and F+M. Like the ninth strategy of Delabastita's, it establishes a second level of communication between a translator and his readers. Its objectives are to stress the translation, to call readers' attention, to compensate what is lost in translation, and to comment on the translation and etc., through a wide range of editorial techniques, such as footnotes, endnotes, special fonts and etc. Each supporting strategy cannot be used alone, instead, it has to be used along with translating strategies as supporting services. In addition, in each case, a translator could use two or more supporting strategies.

\section{Notes:}

1. Theoretically, there might be three- or four-, or more-meaning strategies. In case where a pun has three or four or more meanings, a translator may rendered the pun through non-pun phrase which preserves three, or four, or more meanings. However, it was not identified in the research.

\section{REFERENCES}

[1] Booth, S. (1977). Shakespeare's Sonnets. New Haven: Yale University Press.

[2] Cao Minglun. (1995). Shakespeare Sonnets. Guilin: Lijiang Publishing House.

[3] Delabastita, D. (1993). There Is A Double Tongue: An investigation into the translation of Shakespeare's wordplay, with special reference to Hamlet. Amsterdam: Editions Rodopi.

[4] Drabble, M. (Ed.). (2000). The Oxford Companion To English Literature (the 6th Version ed.). Oxford: Oxford University Press.

\footnotetext{
${ }^{1}$ Theoretically, there might be three- or four-, or more-meaning strategies. In case where a pun has three or four or more meanings, a translator may rendered the pun through non-pun phrase which preserves three, or four, or more meanings. However, it was not identified in the research.
} 
[5] Fung, C. N. (2003). The Application of Delabastita's Theory of Pun Translation to English-Chinese Translation. Chinese Translators Joumal, 24(1). p.33.

[6] Gu Zhengkun. (1998). Shakespeare Sonnets. Beijing: Beijing University Press.

[7] Han Dihou. (1969). Modern Translation History (Jin Dai Fan Yi Shi Hua). Hong Kong: Chenchong Publisher.

[8] Ingram, W. G., \& Redpath, T. (Eds.). (1978). Shakespeare's Sonnets. London: Hodder And Stoughton.

[9] Jin Fashen. (2004). Shakespeare Sonnets. Guilin: Guangxi Normal University Press.

[10] Larudee, P. S. (1973). Puns As Speech Acts And Speech Acts In Grammatical Theory. Ph.D thesis, Georgetown University, Washington.

[11] Li Xinhua (Ed.). (2000). English Rhetorics. Shanghai: Shanghai Foreign Languages Teaching and Research Press.

[12] Liang Shiqiu. (2002). Shakespeare Sonnets (Vol. 40). Beijing: China Radio \& Television Publishing House.

[13] Liang Zongdai. (1983). Shakespeare Sonnets. Chengdu: Sichuan People's Publishing House

[14] Newmark, P. (2001). A Textbook of Translation. Shanghai: Shanghai Foreign Language Education Press.

[15] Reiss, K. (2000). Type, Kind, And Individuality Of Text: Decision Making In Translation (S. Kitron, Trans.). In L. Venuti (Ed.), The Translation Studies Reader (pp. 169). London: Routledge.

[16] Ruan Shen. (2001). Shakespeare Sonnets. Wuhan: Hubei Education Press.

[17] Tu An. (1981). Shakespeare Sonnets. Shanghai: Shanghai Translation Publishing House.

[18] Vendler, H. (1997). The Art of Shakespeare's Sonnets. Cambridge: Harvard University Press.

[19] Yang Xiling. (1980). Shakespeare Sonnets. Hohhot: Inner Mongolia People's Publishing House.

[20] Yu Erchang. (2002). Shakespeare Sonnets. Taibei: World Book Publishing House.
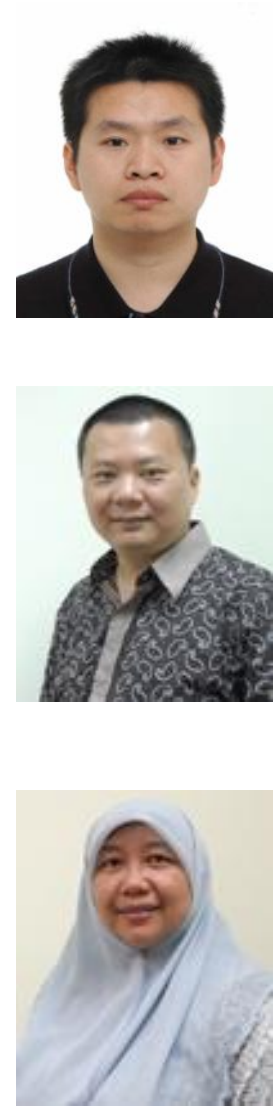

Chengzhi Zhang, born on May 2. 1979, in Hubei, China. He earned his B. A. of English Language and Literature, M.A. in translation Studies from Hebei University, China. He earned his PHD in Translation studies from Univeristi Sains Malaysia in 2014.

Dr. Zhang Chengzhi is currently an associate professor in Hebei University, China. His areas of specialization include literary translation, translation technology, corpus translation, financial translation, translation history and etc.

Goh Sang Seong earns his B.A., M.A., and Ph.D. in Translation Studies from Universiti Sains Malaysia (USM). His Areas of Specialisation includes Translation Studies; Chinese-Malay Translation.

Dr. Goh is now a senior lecturer in Malay Language, Translation and Interpreting Department, School of Humanities, Universiti Sains Malaysia.

Suzana Hj. Muhammad, earned her B.A. of English Education, M.A of English Literature in USA and her $\mathrm{Ph} . \mathrm{D}$ in Literary Criticism from Indiana Univ. Of Pennsylvania, USA. Her Areas of Specialisation include British and American Literature, Literary Theory \& Criticism, Feminism and Women Writers.

Dr. Suzana is currently a senior lecturer in English Language Studies Department, School of Humanities, Universiti Sains Malaysia. 